\title{
Examining the mental models related to sound of pre-service physics teachers in different contexts
}

\author{
Tuğbanur Dinçer ${ }^{1 a}$ and Özgür Özcan ${ }^{1}$ \\ ${ }^{1}$ Hacettepe University, Faculty of Education, Department of Secondary Science and Mathematics \\ Education,06800 Ankara, Turkey
}

\begin{abstract}
This study aims to identify the mental models related to sound of pre-service physics teachers. In this research, case study method which belongs to qualitative research methods was used. 12 pre-service physics teachers, who are currently at the fourth class in the physics education department, participated in this research. In the application process, firstly, researchers asked questions related to sound concept which is prepared for different contexts, to the students and then the simulations are shown related to these questions. The students who obtained the scientifically true answers of these questions by using simulations then explained the reasons of each answer which are wrong, incomplete or contradiction. Mental models of pre-service physics teachers and their understanding difficulties related to sound are revealed by analyzing the data. In conclusion, it is observed that participants have models and understanding difficulties which are also found in the literature. In addition, it is observed that new models and understanding difficulties are revealed.
\end{abstract}

Keywords. Sound; mental model; understanding difficulties; physics education

\section{Introduction}

A model can represent a thought, subject, event, progress or system. Models are also significant in verifying the hypotheses being tested and defining the scientific facts. [5] These models which serve as the indicators of certain perceptions are used by the physicists to differentiate between the facts [11]. There are ten models which can be counted as those by Harrison and Treagust [7] scaling models, pedagogical and analogical models, symbolic and sign models, mathematical models, theoretical models, maps, diagrams and tables, concept-and-process models, simulations, mental models, and those based on synthesis. In

\footnotetext{
${ }^{a}$ Corresponding author: tugbanur_dincer@hacettepe.edu.tr
} 
the field of study, the mental / cognitive models which students have will be analyzed. To comprehend the scientific information, mental models should be structured [6]. The researchers working on the learning process by the science students are face to face with such questions as how science students grasp science subjects, whether they use a mental model or not, - if they use it -how these models can be shaped [10]. Owing to the complexity of the mental models in their nature, the data related to mental models are generally tried to be derived from sources through various models during the study. In the studies on mental modeling, so as to collect data, multiple choice questions, open-ended questions (with drawings and explanations), interviews and observations are applied [1]. In the research field, open-ended questions based on simulation programs regarding sound and also a simulation program was implemented. With this, the changes taking place in the models owned by students have been analyzed. Using simulations especially in teaching abstract concepts help learners visualize difficult concepts in their minds [3]. The subject, "sound", as the subject matter of the study is regarded as one of the most difficult topics to comprehend in physics since it embraces some abstract concepts [9]. From this point onwards, Hrepic, Zollmannand Rebello in 2010 [8] studied on the emission of sound and in this study they put forward three models, which are "Wave Model", "Entity Model" and "Hybrid Model", the combination of the two. With this study, they specified new models to contribute to the field within these contexts.

\section{Method}

\subsection{Design of study}

In this study, in order to get a detailed picture of the models which have been molded in the minds of the students, "situational case study" method has been implemented which enables the researcher to study different cases in depth [12]. There are four different types of case studies, which are; "holistic single case study", "single case with embedded units", "holistic multiple case study" and "multiple cases with embedded units". Within the framework of this study, integrated one case pattern method [13] has been utilized in such cases as a unit of analysis (one individual, one institution, one program, etc.) which has not been studied by anyone, and which will serve as basis for the following studies in the future as a contribution.

\subsection{Participants}

In this study, "Criterion Sampling", one of sampling methods, has been used. This method enables one to conduct a deeper analysis via choosing a certain group [4]. Thus, we studied with 12 candidate teachers studying physics in the fourth grade, who took "Vibration and Waves" class and successfully completed the course. Within the study group, there are 10 female and two male student teachers of physics, the ages ranging between 21 and 24 .

\subsection{Data collection and analysis}

The qualitative data used in this study are collected via open-ended questions based on an educational simulation program - accessible to anyone on the Internet. These questions include five contexts and they have been asked to the candidate teachers prior to the simulation. Afterwards, the simulation program has been shown to the participants, asked to comment on the questions and to give reasons for the answers they gave with explanations. The interviews were conducted by the researchers and took around $15-20$ minutes. 
In the first one of these contexts, the question, "how the sound from two different sources at different frequencies would emit" was asked to the students and draw the possible pattern on a piece of paper given. In the second part, they were asked to show the emittance of the sounds coming from two identical source of sound adjacent to each other and expected to draw the interference there. Also, if possible, they were asked to indicate where the sounds are inaudible. In the third context, they were asked to show by drawing what might happen when the sound from a source meets a surface within the area given. In the fourth context, they were asked to state how the sound would emit in a given airless medium. In the last and fifth context, they were asked to indicate which of the properties of the sound they would be changing if they were to turn down a radio on identical sources given.

These qualitative data gathered at the end of this procedure have been analyzed through content analysis method. Moreover, "models" have been structured looking at the similarities and differences between categories [2]. After the analysis conducted, there emerged two types of wave models related to the concept of sound and they were called "Wave Model Type 1" and "Wave Model Type 2". The models have been determined depending on the criteria below:

Wave Model Type 1 (WM-T1): This model is represented as spherical wave emitted from a source (Fig. 1).

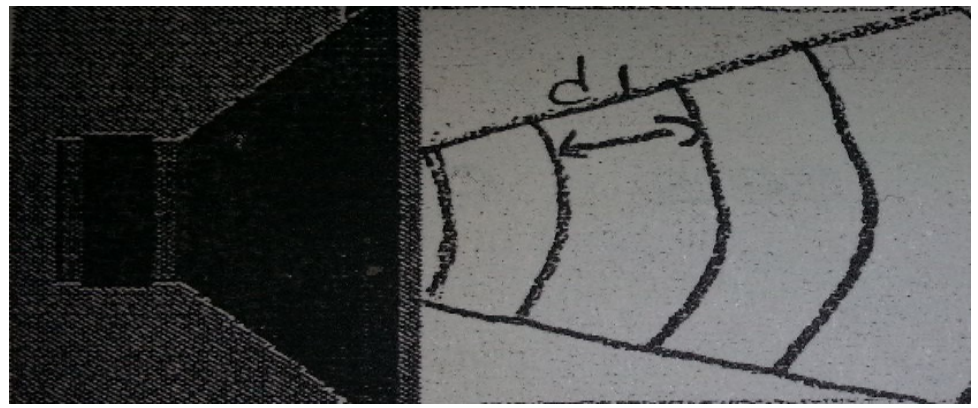

Fig. 1. Wave Model Type 2(WM-T2): In this model, the sound wave emitted from a source of sound is represented as sinusoidal wave

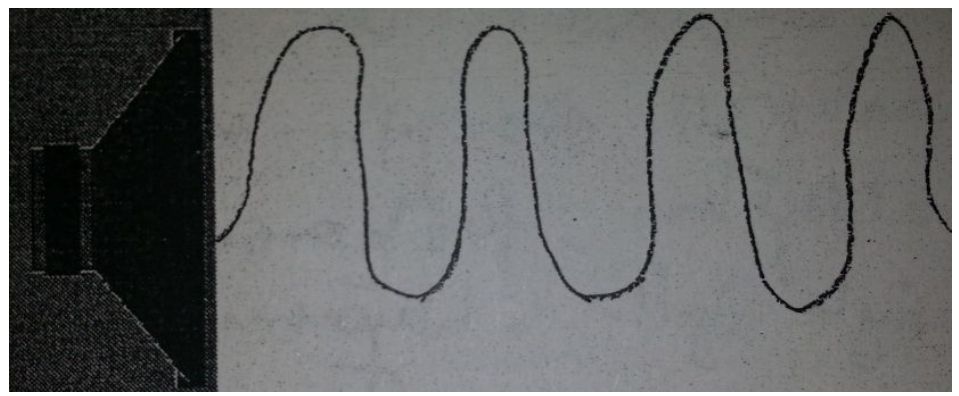

Fig. 2. Wave model type 2

After the analyses conducted, it was concluded that the students - participants - can be categorized under three headings depending upon their level of understanding: "complete understanding", "incomplete understanding," and "misunderstanding." 


\section{Results}

When the answers prior to this procedure have been analyzed, it has been found out that the participants have the "Wave Models" types shown in the table below. For each context, all the models which participants possess have been analyzed and found out whether the model they chose is regarded as "Pure Model State" or "Mixed Model State" (Table 1).

Table 1. Participants models depending on contexts.

\begin{tabular}{lcccccccccccc}
\hline & S1 & S2 & S3 & S4 & S5 & S6 & S7 & S8 & S9 & S10 & S11 & S12 \\
\hline Context 1 & T1 & T2 & NM & T2 & T2 & T1 & T1 & T1 & T1 & T1 & T1 & T2 \\
Context 2 & T1 & T1 & T1 & T2 & T1 & T1 & T1 & T1,T2 & T1 & T1 & T1 & T2 \\
Context 3 & T1 & T1 & T1 & T2 & T1 & T1 & T1 & T1 & T1 & T1 & T1 & T2 \\
Context 4 & T1 & T1 & T1 & T2 & T1 & T1 & T1 & T1 & T1 & NM & T1 & T2 \\
Context 5 & T2 & T1 & T1 & T2 & T2 & T1 & T1 & T2 & T2 & T1 & T2 & T2 \\
Model State & Mix & Mix & Pure & Pure & Mix & Pure & Pure & Mix & Mix & Mix & Mix & Pure \\
\hline
\end{tabular}

T1: Wave model type 1, T2: Wave model type 2, NM: No Model

When we look at the models as a whole, we see that certain participants consistently have the same or similar scientific models in all contexts; they somehow put forward wrong conclusions while interpreting the content. For instance, although they used "Wave ModelType 1" for the emission of the sound from a source, they preferred to use higher frequency for a lower one and vice versa while indicating different frequencies. That's to say, though modeling the emission of the sound in the correct way; they were mistaken with misleading deductions in interpreting the parameters related to sound. As seen in Table 1, instead of using the same model between contexts in a consistent manner, they opted for a different model in each context. While seven participants are "Mixed Models" in their answers to the contexts, five being "Pure Models". Three of these five models were "Wave Model-Type 1 " whereas two were "Wave Model-Type 2". In the simulation show of the third context, it is seen that the sound hits an obstacle and bounces back altogether. But, this has been detected by students and commented that the sound must have lost some of its energy and might go beyond the obstacle as a contribution. It was also pointed out that sound waves cannot progress themselves and that it can move from one place to another by transferring its energy from one molecule to another. Different from the other participants, the subject called S10 commented on the context four related to the question how sound travels in the airless medium that waves' progress in a linear form in the medium instead of diffusing in a circular way since there is no air there. The participant stated that, in order for the sound to travel in circles, it needs a materialistic medium, if it does not exist, it will travel in a linear form. After the simulation, it was found out that the best model which represents all the students have is "Wave Model-Type 1" scientifically denoted.

\section{Discussion and conclusion}

In this study, the mental models and understanding difficulties of the students who study physics in their fourth year have been put forward and their transfer of knowledge to their future students have been determined as candidate teachers of tomorrow. The findings acquired seem to have contributed to the models in this study as they overlap with them, too. In brief, it has been found out that, prior to the study, the participants have two distinct 
mental models which can be counted as "Wave Model Type 1" and "Wave Model Type 2". Their comprehension level has been understood to cover these three categories; "complete understanding", "incomplete understanding," and "misunderstanding."

"Wave Model Type 1" is the model where the participants perceive sound waves as spherical wave, whereas in "Wave Model Type 2", they modeled these waves as sinusoidal waves. The basic reason which was determined through interviews can be expressed as follows: The students who apply Type 1 model stated that sound waves are pressure waves and thus assumed that they would travel in circles. Those who fall into Model Type 2 stated that they confused the sound waves with electromagnetic waves or they interpreted the sound waves as sinusoidal waves on xy- plane based on wrongly drawings in textbooks and thus they modeled them in sinusoidal form.

Another point, determined from the answers given by the participants before the simulations applications is that their answers to the questions related to sound were based on unscientific foundations and they confused the terms with each other. That's to say, inasmuch as they modeled the sound waves in the correct way, some students gave answers which are far away from scientific facts as a whole. This shows us that they lack some basic subjects in some parts of the topic.

At the end of the study, all the participants completed their lack of knowledge by transferring to Wave Model Type 1 - which represents the scientific model in the best way.

As a conclusion, in teaching this kind of topics which are difficult to grasp by students, using simulations has been concluded to be effective in meaningful learning and also in visualizing mental models in a way that is closer to scientific reality.

\section{References}

1. Chia-Yu, W. The role of mental-modeling ability, content knowledge, and mental models in general chemistry students' understanding about molecular polarity. Dissertation of Philosophy. The Faculty of the Graduate School University of Missouri, (2007).

2. Creswell, J. W. Nitel araştırma yöntemleri - Beş yaklaşıma gore nitel araştırma ve araştırma deseni (Çev. Ed: Bütün, M. \&Demir, S.B.)Ankara: Siyasal Kitabevi, (2013).

3. Demirci, N. Bilgisayarla etkili öğretme stratejileri ve fizik öğretimi, Ankara: Nobel Yayıncilık, (2003).

4. Fraenkel, J.R., \& Wallen, N.E. How to design \& evaluate research in education. Boston: McGraw Hill, (2006).

5. Gilbert, J. K., \& Boulter, C. J. Stretching models too far, Annual Meeting of the American Educational Research Association. San Francisco, (1995).

6. Greca, I.M., \& Moreira, M.A. Mental models, conceptual models, and modeling. International Journal of Science Education, 22, 1-11, (2001).

7. Harrison, G. A., \& Treagust, F.D. A typology of school science models. International Journal of Science Education, 22(9), 1011-1026, (2010).

8. Hrepic, Z., Zollman, D. A., \& Rebello, N. S. Identifying students' mental models of sound propagation: The role of conceptual blending in understanding conceptual change. Physical Review Special Topics-Physics Education Research, 6, 020114, (2010).

9. Merino, M. J. Some difficulties in teaching the properties of sounds. Physics Education, 33(2), 101-104, (1998).

10. Plumb, M. S. Student interpretations of electric and magnetic fields and forces on the CSEM. Unpublished Doctoral Dissertation. The State University of New York, (2003). 
11. Redish, E. F. A theoretical framework for physics education research: modeling student thinking, in Proceedings of the International School of Physics "Enrico Fermi", Course CLVI, , E. F. Redish \& M. Vicentini (eds.) 1-64 (IOS Press, Amsterdam, 2004), (2004).

12. Yıldırım, A., \& Şimşek, H. Sosyal bilimlerde nitel araştırma yöntemleri (6. Bask1). Ankara: Seçkin Yayıncılık, (2008).

13. Yin, R. K. Case study research: Design and methods. Beverly Hills, CA: Sage Publications, (1984). 